\title{
Phase transitions and formation of polytypes in crystal structures of ionic compounds
}

\author{
E.M. SLYUSARENKO ${ }^{1} *$ \\ ${ }^{1}$ Department of Chemistry, Lomonosov Moscow State University, Leninskie Gory, 119992 Moscow, \\ Russian Federation \\ * Corresponding author. E-mail: slusarenko@laincom.chem.msu.ru
}

Received September 16, 2007; accepted December 29, 2008; available on-line March 19, 2009

In the present investigation a new approach for a design of system of chemical bonds in crystals - geometric conception of chemical bond (GCCB) - has been used. In GCCB the term "chemical bond", the shape of the atoms and the relative dimensions of the valence orbitals of the atoms are strictly determined in initial postulates that allow to obtain a full collection of all possible valence configurations of the atoms. The configurations of excited atoms are used as the elements for design of crystal structures. Models of systems of chemical bonds in basic structural types of ionic compounds have been created.

Ionic radii / Ionic bond

\section{Introduction}

The modern conception of ionic bonds between atoms is formed by two versions of structure modeling.

In the classical version an ionic bond is formed by the full transfer of an electron from one atom to another with ions forming and the bond between the ions of electrostatic nature. Within the limits of this approach the atoms are represented as point charges having an electromagnetic field of spherical symmetry, the size of the donors being decreased and that of the acceptors being increased. This conception has developed a formal description of these bonds (tables of ionic radii, terms such as oxidation degree, electrovalence, etc.) that is still being used in the field of education and research in chemistry.

At present the ionic bond is more often represented as a limit case of a polar covalent bond that corresponds to the majority of theoretical and experimental data of ionic compounds. But this method does not succeed in creating a simple and harmonious formalism in ionic bond theory. Although the successful use of quantum mechanics theory in the description of polar covalent bonds of electrons is not to be questioned, the theory itself excludes strict determination of the shape of the atoms. The term "chemical bond" determined as the energy minimum does not allow classifying unambiguously molecules and crystal structures according to the type of chemical bond.

The present investigation has been carried out to solve some problems connected with the application of the system of ionic radii for predictions. The geometric conception of the chemical bond (GCCB) $[1,2]$ has been used.

\section{Geometric conception of the chemical bond}

In the geometric conception of the chemical bond (GCCB) the shape of the atoms and the term "chemical bond" are strictly determined in the initial postulates.

In GCCB the orbit of an electron is a surface with a constant radius of curvature (sphere). $s$-orbits consist of one sphere (Fig. 1a), whereas $p$-, $d$ - and $f$-orbits consist of three, five and seven identical spheres, respectively, as shown in Fig. 1b-d.

Orbits of each type are combined in a system with a common central sphere and outer spheres (valence spheres), which take part in forming chemical bonds. New system of orbits is formed by means of the quantization of volume of the space occupied by $s$-orbit (the volume of spheres in the new system of orbits is equal to the volume of the $s$-sphere).

$V_{s}=7 V_{p}=21 V_{d}=43 V_{f}$

The diameters of the spheres are strictly interconnected by the following ratio:

$D_{s}: D_{p}: D_{d}: D_{f}=1.000: 0.523: 0.362: 0.285$. (1) Modification of the dimensions of one of the orbits immediately leads to changes of all the others according to (1). The only case when a chemical bond between atoms is formed is when the valence spheres of orbits are contiguous, as shown in Fig. 2. 


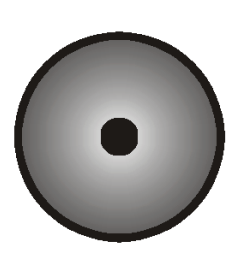

a)

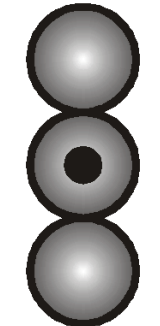

b)

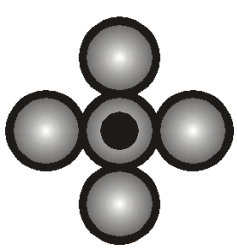

c)

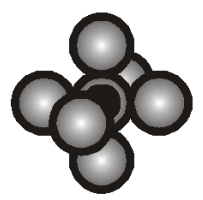

d)

Fig. 1 Configuration of orbits in GCCB: a) $s$-orbit, b) $p$-orbit, c) $d$-orbit, d) $f$-orbit.

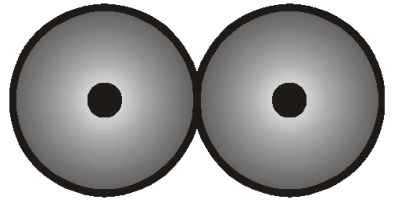

a)

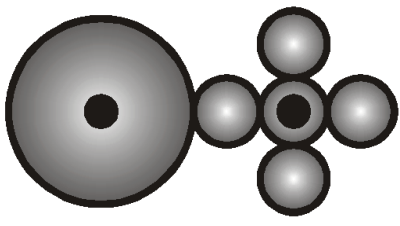

b)

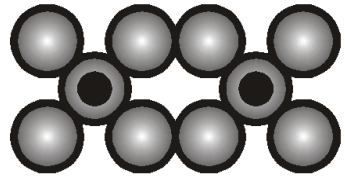

c)

Fig. 2 Formation of chemical bonds: a) $s-s$ bond, b) $s$ - $d$ bond, $d-d$ bond.

At the point of contact of the spheres the electron is indiscernible for both atoms and is able to pass to the electronic system of the other atom. This possibility of exchange of electrons increases significantly the stability of a molecule or crystal with respect to external influence.

In GCCB a reacting atom forms electronic bonds in three states: electronic ground state, state of electronic excitation and state of orbital excitation.

There exist only eight configurations of atoms in the ground state. Four of them are shown in Fig. 1. The configuration of an atom with two and three $p$-orbits is similar to that of an atom with a $d$ - and f-orbit (Fig. 1), respectively, but is of larger dimensions, as it results from (1). Configurations of atoms with two and three $d$-orbits are shown in Fig. 3.

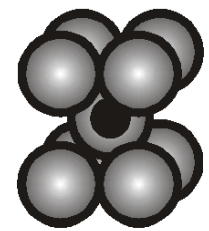

a)

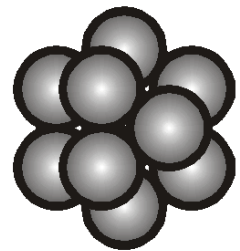

b)
Fig. 3 Valence configurations of atoms in the ground state: a) $d^{2}$-state, b) $d^{3}$-state.

The number of ground states of the atoms is too small to form the variety of molecules and crystals. Atoms usually react in the states of electronic excitation. In an state of electronic excitation electrons pass from the orbits of one system to another. Though it needs spending of energy this is compensated by the formation of more bonds and/or stronger bonds. The configuration of atoms in electronic excitation is a superposition of atomic configurations in the ground state (Fig. 4a-c).

However, also the number of the states of electronic excitation is insufficient to model the structures of even such simple molecules as water, methane, etc. Atoms in the state of orbital excitation are necessary to model these molecules. At orbital excitation the valence spheres, located orthogonally, are displaced from their positions and their centers are disposed at other angles. The angles correspond to the angles between centers of the valence spheres in close-packed structures. A few examples of orbital excitation of atoms are shown in Fig. 5.

\section{Modelling of crystal structures of compounds with ionic bonds}

\section{$\mathrm{NaCl}$ structure}

All compounds of alkali metals with halogens have $\mathrm{NaCl}$ structures (Fig. 6a) and are considered to be classical ionic compounds. However, the metals of main group II form the same structure with elements of main group VI, and many more elements including transition metals and $f$-metals with elements of main group V. Cations and anions form two identical f.c.c. frameworks, one of them filling the octahedral voids of the other one (Fig. 6a).

Alkali metal atoms can exist in ground state $s^{1}$ and the halogen atoms have ground state $s^{2} p^{5}$. However, crystal formation is unlikely (although possible) in this state since the atoms cannot form $s-s$ bonds (the $s$-orbit of the halogen atom is full). Consequently halogen atoms get into the state of electronic excitation, changing to a valence $s$-state $\left(s^{1} p^{6}\right)$. The system of chemical bonds between atoms in the $\mathrm{NaCl}$ structure is shown in Fig. 6b-c. 


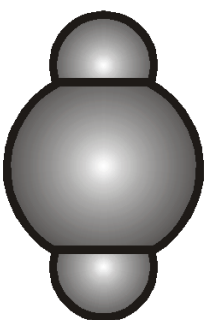

a)

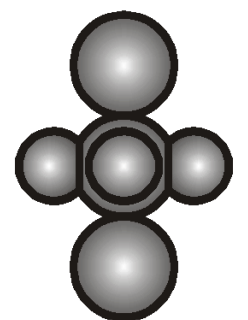

b)

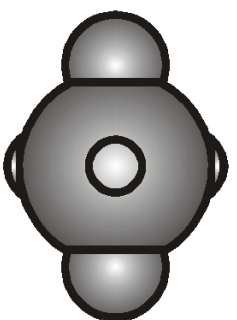

c)

Fig. 4 Configurations of atoms in the states of electronic excitation: a) $s^{1} d^{1}$, b) $p^{1} d^{1}$, c) $s^{1} p^{1} d^{1}$.
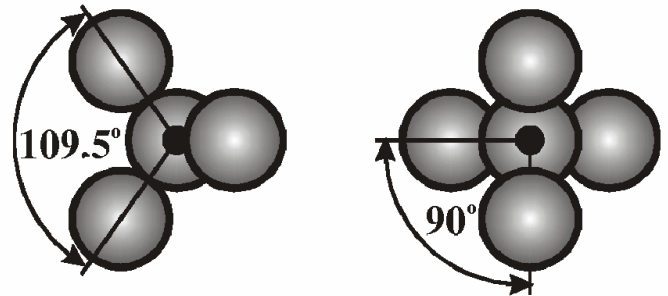

a) 4 spheres (tetrahedron- $p_{2}, d_{1}$ )
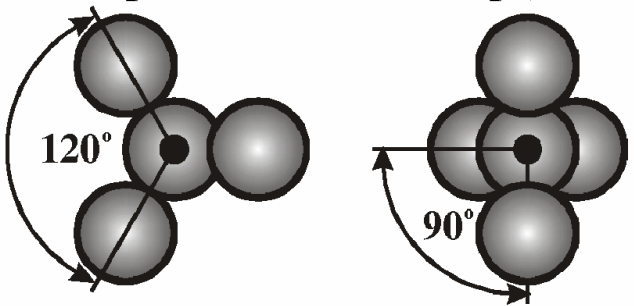

b) 4 spheres (irregular tetrahedron- $\mathrm{p}_{2}, \mathrm{~d}_{1}$ )
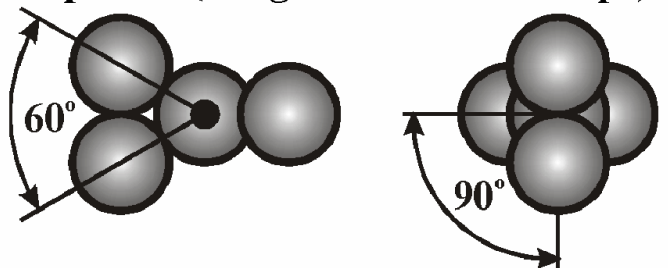

c) 4 spheres (irregular tetrahedron- $p_{2}, d_{1}$ )
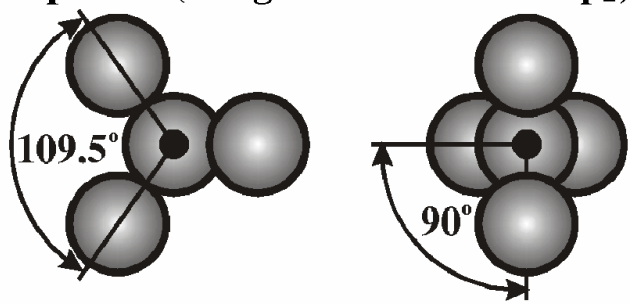

d) 4 spheres (irregular tetrahedron- $\mathrm{p}_{2}, \mathrm{~d}_{1}$ )

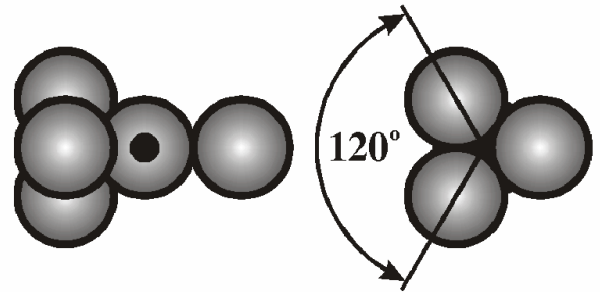

e) 4 spheres (trigonal pyramid-p $p_{2}, d_{1}$ )
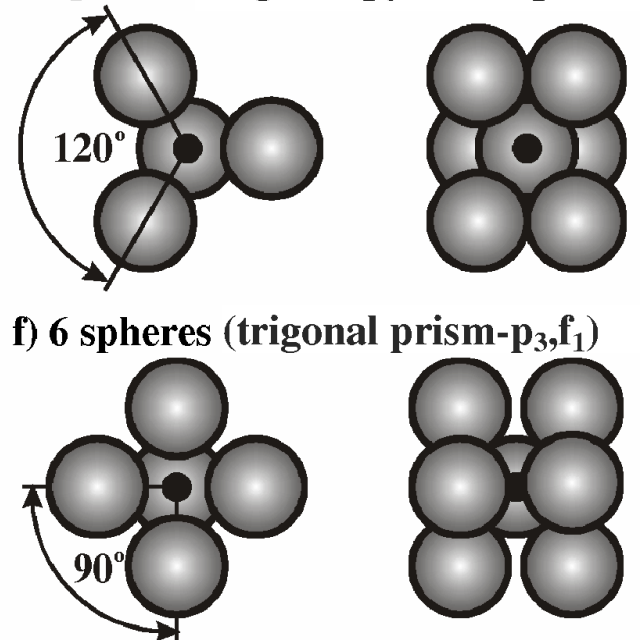

g) 8 spheres (cube-d 2 )
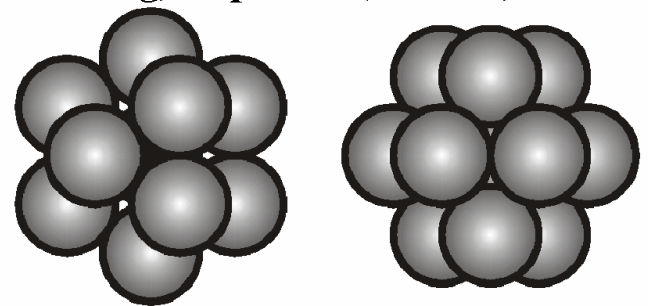

h) 12 spheres (hex. cubooctahedron- $d_{3}, f_{2}$ )

Fig. 5 Configuration of atoms in the states of orbital excitation. The configurations shown above are used for modeling ionic crystal structures.

Due to the $p$-orbits the anions form endless chains in square-mesh layers interconnected by cations. The valence $s$-spheres of the metal atoms create polar covalent bonds with the valence $s$-spheres of the halogen atoms. In each neighboring layer the chains of halogen atoms are oriented orthogonally. The cations form two types of bond with the anions: $s$-s bonds (Fig. 6b) and $s-p$ bonds (Fig. 6c). As a rule the second case is rare since $s-p$ bonds have weak polarizability. These bonds are possible when weak donors interact 


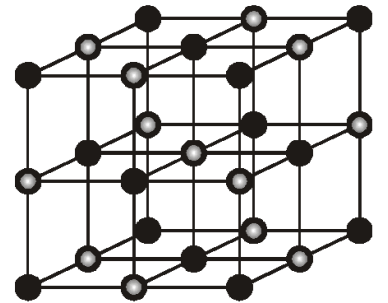

a)

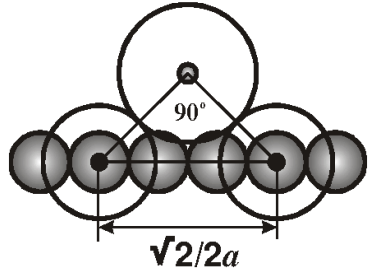

b)

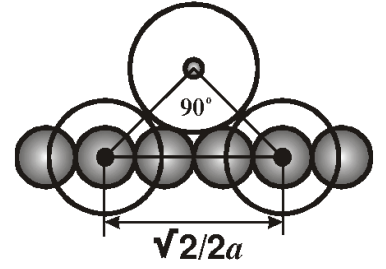

c)

Fig. 6 Calculation of the atomic radii in $\mathrm{NaCl}$ structures: a) crystal structure, b) calculation of the atomic radii for $s-s$ bonds between cations and anions, c) calculation of the atomic radii for $s-p$ bonds between cations and anions.

with weak and large acceptors (for example LiI, BeTe, $\mathrm{BP}, \mathrm{BaS}$, and so on).

Such a system of chemical bonds is formed only at the correlation of ion dimensions. The radii of the anions and cations can easily be calculated from Fig. 6 using correlation (1). If $s$-s bonds form between the cations and anions, the radii of the atoms may be calculated as shown in Fig. 6b.

$$
\begin{aligned}
& r_{s}(\mathrm{Cl})=\frac{\sqrt{2}}{12 \times 0.5228} a=0.2254 a \\
& r_{s}(\mathrm{Na})=a / 2-r_{s}(\mathrm{Cl})=0.2746 \\
& r_{s}(\mathrm{Na}) / r_{s}(\mathrm{Cl})=1.2179
\end{aligned}
$$

If $s-p$ bonds form between the cations and anions, the radii of the atoms may be calculated as shown in Fig. 6c.

$$
\begin{aligned}
& r_{p}(\mathrm{Cl})=\frac{\sqrt{2}}{12} a=0.1179 a \\
& r_{s}(\mathrm{Na})=a \sqrt{5} / 6-r_{p}(\mathrm{Cl})=0.2548 a \\
& r_{s}(\mathrm{Na}) / r_{s}(\mathrm{Cl})=1.1303
\end{aligned}
$$

The calculated values of the ionic radii are within the range between the metallic or covalent radii of the atoms and their ionic radii.

Metals of main group II and elements of main group VI form $\mathrm{NaCl}$ structures with the same system of chemical bonds. Values of atomic radii in $\mathrm{NaCl}$ structures and others are listed in Table 2. However, in this case the metal atom transfers one electron to the system of $p$-orbits of the acceptor and ions $\mathrm{C}^{+}$and $A^{-}$ that are isoelectronic to alkali metals and halogens are formed. Thus, only one pure ionic bond is present in these structures. Ionic radii have been calculated and are given in Table 2. Beryllium and to some extent magnesium are not able to form $\mathrm{NaCl}$ structures because of the small dimensions of the cation. In this case $\mathrm{ZnS}$ structures (cubic and hexagonal) are formed.

Metals atoms of main group III are not able to form $\mathrm{NaCl}$ structures with elements of main group $\mathrm{V}$. For nitrogen and its analogues it is necessary to take away two electrons from the metal atom, but nitrogen and its analogues do not have this capacity. Combinations of these elements give different structures (Table 3). As a rule, $\mathrm{ZnS}$ (cub) or $\mathrm{ZnS}$ (hex) structures are formed.

\section{CsCl structure}

Anions of larger dimensions and of element with a high electron affinity form a different cubic (b.c.c.) structure - $\mathrm{CsCl}$ (Fig. 7). In this structure the cations and anions form two identical simple cubic substructures (Fig. 7a). The atoms have valence configurations as in the $\mathrm{NaCl}$ structure and the anions form bonds along the diagonal of the cube face. Hence

\begin{tabular}{|c|c|c|c|c|}
\hline $\begin{array}{l}\text { Element } \\
\text { covalent } r \\
\text { ionic } r \text { [3] }\end{array}$ & $\begin{array}{c}F \\
r_{F}=0.71 \\
r_{A}=1.33\end{array}$ & $\begin{array}{c}C l \\
r_{C l}=1.00 \\
r_{A}=1.81\end{array}$ & $\begin{array}{c}B r \\
r_{B r}=1.14 \\
r_{A}=1.96\end{array}$ & $\begin{array}{c}I \\
r_{I}=1.33 \\
r_{A}=2.20\end{array}$ \\
\hline $\mathbf{L i}$ & 1.106 & 1.411 & 1.510 & 1.650 \\
\hline $\begin{array}{l}r_{L i}=1.55 \\
r_{C}=0.68\end{array}$ & 0.908 & 1.159 & 1.240 & $\begin{array}{c}1.356 \\
\left(\mathbf{Z n S}_{\mathbf{c}}\right) \mathbf{h p} \\
1.312 \\
1.428 \\
\end{array}$ \\
\hline $\mathbf{N a}$ & 1.270 & 1.548 & 1.640 & 1.777 \\
\hline $\begin{array}{l}\mathbf{r}_{\mathrm{Na}}=1.89 \\
\mathbf{r}_{\mathrm{C}}=\mathbf{0 . 9 7}\end{array}$ & 1.044 & 1.272 & 1.347 & 1.460 \\
\hline $\mathbf{K}$ & 1.467 & 1.727 & 1.811 & 1.940 \\
\hline $\begin{array}{l}r_{K}=2.35 \\
r_{C}=1.33\end{array}$ & 1.205 & 1.419 & 1.488 & 1.593 \\
\hline $\mathbf{R b}$ & 1.548 & 1.760 & 1.885 & 2.015 \\
\hline $\begin{array}{c}r_{R b}=2.48 \\
r_{C}=1.47\end{array}$ & 1.272 & $\begin{array}{c}1.446 \\
(\mathbf{C s C l}) \\
1.555 \\
1.691 \\
\end{array}$ & 1.549 & 1.655 \\
\hline Cs & 1.652 & 1.905 & 1.985 & 2.103 \\
\hline $\begin{array}{l}r_{\mathrm{Cs}}=2.68 \\
r_{C}=1.67\end{array}$ & 1.358 & $\begin{array}{c}1.565 \\
(\mathbf{C s C l}) \\
1.746 \\
1.900\end{array}$ & $\begin{array}{c}1630 \\
(\mathbf{C s C l}) \\
1.782 \\
1.938\end{array}$ & $\begin{array}{c}1.727 \\
\text { (CsCl) } \\
1.894 \\
2.061\end{array}$ \\
\hline
\end{tabular}
the dimensions of the cations and anions are easily calculated as shown in Fig. 7b-c.

Table 1 Atomic radii $(\AA)$ of alkali metal and halogen elements; $\mathrm{NaCl}$ structure if no other indication. 
Table 2 Atomic radii $(\AA)$ of elements of main groups II and $\mathrm{VI}$; $\mathrm{NaCl}$ structure if no other indication.

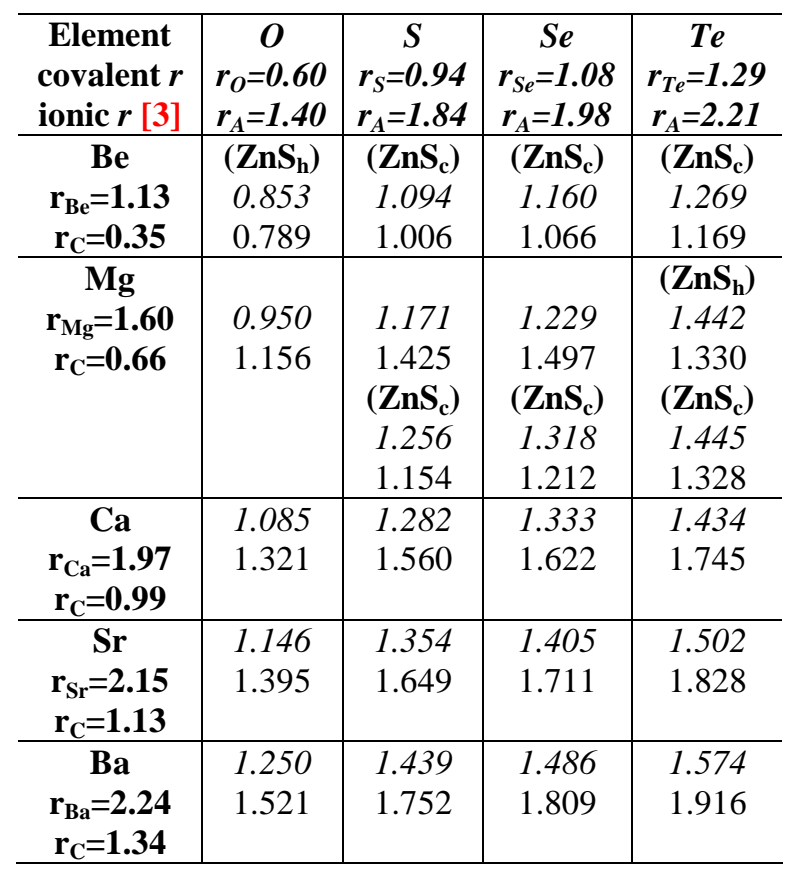

Table 3 Atomic radii $(\AA)$ of elements of main groups I and VI; anti- $\mathrm{CaF}_{2}$ structure if no other indication.

\begin{tabular}{|c|c|c|c|c|}
\hline $\begin{array}{l}\text { Element } \\
\text { covalent } \boldsymbol{r} \\
\text { ionic } \boldsymbol{r}[3]\end{array}$ & $\begin{array}{c}O \\
r_{O}=0.60 \\
r_{A}=1.40\end{array}$ & $\begin{array}{c}S \\
r_{S}=0.94 \\
r_{A}=1.84\end{array}$ & $\begin{array}{c}S e \\
r_{S e}=1.08 \\
r_{A}=1.98\end{array}$ & $\begin{array}{c}T e \\
r_{T e}=1.29 \\
r_{A}=2.21\end{array}$ \\
\hline $\mathbf{L i}$ & 1.043 & 1.287 & 1.354 & 1.466 \\
\hline $\begin{array}{l}r_{L_{i}}=1.55 \\
r_{C}=0.68\end{array}$ & 0.961 & 1.185 & 1.247 & 1.350 \\
\hline $\mathrm{Na}$ & 1.254 & 1.474 & 1.538 & 1.649 \\
\hline $\begin{array}{c}r_{\mathrm{Na}}=1.89 \\
r_{\mathrm{C}}=0.97\end{array}$ & 1.154 & 1.357 & 1.416 & 1.519 \\
\hline $\mathbf{K}$ & 1.454 & 1.666 & 1.796 & 1.837 \\
\hline $\begin{array}{l}r_{K}=2.35 \\
r_{C}=1.33\end{array}$ & 1.339 & 1.540 & 1.597 & 1.691 \\
\hline $\begin{array}{c}\mathrm{Rb} \\
\mathrm{r}_{\mathrm{Rb}}=2.48 \\
\mathrm{r}_{\mathrm{C}}=\mathbf{1 . 4 7}\end{array}$ & $\begin{array}{l}1.523 \\
1.402\end{array}$ & $\begin{array}{l}1.729 \\
1.592\end{array}$ & \multicolumn{2}{|c|}{ (other structures) } \\
\hline $\begin{array}{c}C s \\
r_{C s}=2.68 \\
r_{C}=1.67\end{array}$ & & & & \\
\hline
\end{tabular}

When $s-s$ bonds form between the cations and anions (Fig. 7b) the radius of the anion is $r_{A}=0.4509 a$, and that of the cation is $r_{C}=0.4151 a$. In this structure the anions are larger than the cations $\left(r_{C} / r_{A}=0.9207\right)$. Calculated ionic radii are given in Table 1. For $s-p$ bonds forming between the cations and anions $r_{C} / r_{A}=0.7032$.

This structure is typical for large cations that are strong donors.

\section{$\mathrm{CaF}_{2}$ and anti-CaF structures}

The $\mathrm{CaF}_{2}$ structure is formed by removing half of the cations from the $\mathrm{CsCl}$ structure with double cell (Fig. 8a-b). As a result the coordination of the anions becomes tetrahedral, whereas the cations retain the cubic coordination. The same operation for the anions leads to the anti- $\mathrm{CaF}_{2}$ structure (Fig. 8c).

When $s$ - $s$ bonds form between cations and anions (Fig. 7b) the radius of the anion is $r_{A}=0.2254 a$, and the radius of cation is $r_{C}=0.2076 a$, as in the $\mathrm{CaF}_{2}$ structure. The cations are smaller than the anions $\left(r_{C} / r_{A}=0.9207\right)$. Calculated ionic radii are given in Table 3 .

\section{ZnS (cubic) structure}

The cubic $\mathrm{ZnS}$ structure is also a defect $\mathrm{CsCl}$ structure. The $\mathrm{ZnS}$ structure is formed by simultaneous removal of half of the cations and anions from the $\mathrm{CsCl}$ structure with double cell $\left(a=2 a^{\prime}\right)$ as shown in Fig. 8a-c. The coordination of both the anions and the cations is tetrahedral in the $\mathrm{ZnS}$ structure. The anions form straight chains by $p-p$ bonds ( $p$-orbits in ground state) along the diagonal of the cube side. In the $\mathrm{ZnS}$ structure the system of chemical bonds and the ratio of the radii are the same as in $\mathrm{CaF}_{2}$. When $s$ - $s$ bonds form between cations and anions (Fig. 7b) the radius of the anion is $r_{A}=$ $0.2254 a$, and the radius of the cation $r_{C}=0.2076 a$, as in the $\mathrm{CaF}_{2}$ structure. The dimensions of the cations are less than those of the anions $\left(r_{C} / r_{A}=0.9207\right)$.

This structure is typical for cations of small dimensions and weak donors such as beryllium. Calculations of the ionic radii in real compounds are given in Tables 1-3.

\section{ZnS (hexagonal) structure}

The hexagonal variant of $\mathrm{ZnS}(a=3.823, c=6.261 \AA$; $c / a=1.6377$ ) is more rarely observed. It is formed by two close-packed hexagonal substructures generated by the cations and the anions, respectively (Fig. 10a).

The radii of the atoms and the ratio $r_{C} / r_{A}$ are related to the interaxial ratio $c / a$. The values are easily calculated from geometric relations, as shown for $\mathrm{ZnS}$. Firstly the angle $\alpha$ (tetrahedral angle modified by the relative displacement of the atoms) has to be calculated (Fig. 10c-d).

$$
\begin{aligned}
& 2 \alpha=109.47122^{\circ}-2 \operatorname{arctg}(\sqrt{3} c / 2 a)= \\
& 0.078015
\end{aligned}
$$

The diameter of the $p$-sphere of the $\mathrm{S}$ atoms is determined from equation (9).

$$
D_{p}(\mathrm{~S})=\frac{\sqrt{c^{2} / 4+a^{2} / 3}}{2 \cos \alpha+\sqrt{1-4 \sin ^{2} \alpha}}=1.2768
$$

The radius of the $s$-sphere of the $\mathrm{S}$ atom is calculated by relation (10)

$$
r_{s}(\mathrm{~S})=D_{p}(\mathrm{~S}) / 2 \times 0.52276=1.2212
$$

and the radius of the $s$-sphere of the $\mathrm{Zn}$ atom by equation (11). 


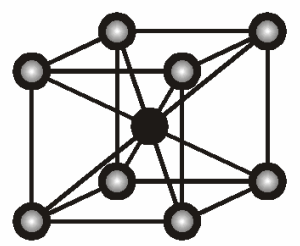

a)

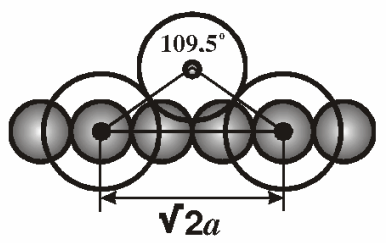

b)

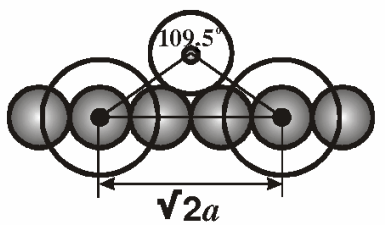

c)

Fig. 7 Calculation of the atomic radii in $\mathrm{CsCl}$ structures: a) crystal structure, b) calculation of the atomic radii for $s-s$ bonds between cations and anions, c) calculation of the atomic radii for $s-p$ bonds between cations and anions.

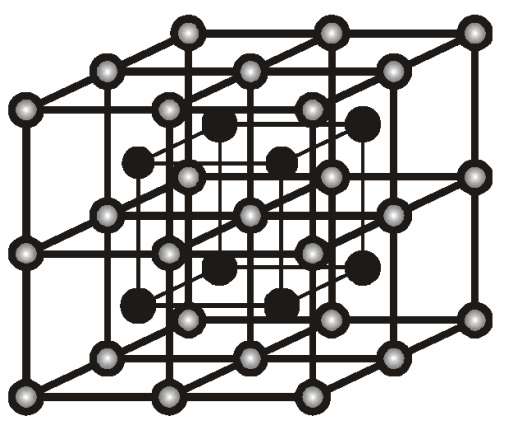

a)

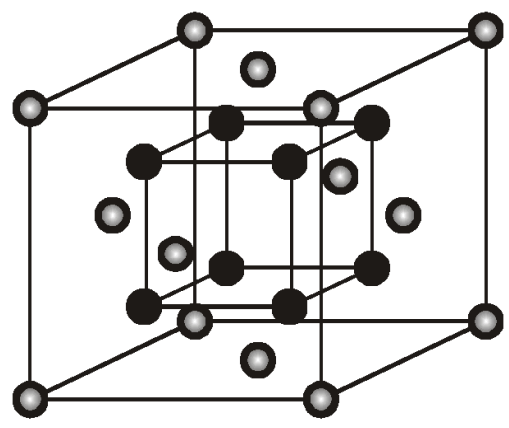

b)

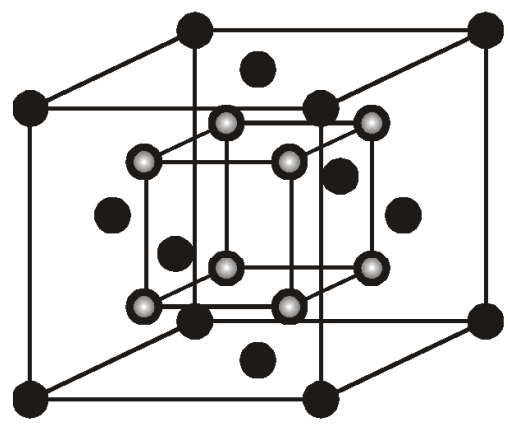

c)

Fig. 8 Formation of the $\mathrm{CaF}_{2}$ and anti-CaF $\mathrm{CaF}_{2}$ structures: a) $\mathrm{CsCl}$ structure $\left(a^{\prime}=2 a\right)$, b) $\mathrm{CaF}_{2}$ structure, c) anti$\mathrm{CaF}_{2}$ structure.

$$
\begin{aligned}
& r_{s}(\mathrm{Zn})=d_{\mathrm{ZnS}}-r_{s}(\mathrm{~S})= \\
& \left(c / 4+a^{2} / 3 c\right)-1.2212=1.1222
\end{aligned}
$$

The ratio of the radii

$r_{s}(\mathrm{Zn}) / r_{s}(\mathrm{~S})=0.9189$.

Tables 2-3 list values of calculated ionic radii.

\section{Polytypes of ionic compounds}

In addition to $\mathrm{ZnS}$ (cub) with $\mathrm{ABC}$ stacking of closepacked anion layers and $\mathrm{ZnS}$ (hex) with $\mathrm{AB}$ stacking of close-packed anion layers, several tens of modifications of $\mathrm{ZnS}$ with different stacking of layers have been determined $[4,6]$.

The formation of these compounds, so-called polytypes, is evident from the point of view of GCCB. If in the structure of $\mathrm{ZnS}$ the atoms of the anions forming the layer are in the ground state, the formation of next layer leads to cubic stacking (ABC). If the atoms of the anions forming the layer are in the state of orbital excitation, the formation of the next layer leads to hexagonal stacking (ABA). The ratio of cubic and hexagonal stacking is determined by the correlation of orbital excited atoms and non-excited atoms under the existing conditions.

\section{$\mathrm{Na}_{3} \mathrm{As}$ structure}

In the $\mathrm{Na}_{3} \mathrm{As}$ structure $(a=5.098, c=9.000 \AA)$ orbital excited atoms of the anions form zigzag chains along the $c$-axis by $p$ - $p$ bonds, as in the $\mathrm{ZnS}$ (hex) and $\mathrm{NiAs}$ structures (Fig. 11a). Phases with this structure have a practically constant cell parameter ratio, $c / a=1.79 \pm 0.03$ [4], as for $\mathrm{ZnS}$.

The radius of the anion in the structure is calculated by equations (8-10). In $\mathrm{Na}_{3} \mathrm{As}$

$r_{s}(\mathrm{As})=1.717 \AA$.

The cations occupy two different positions in this structure. Na1 atoms center a triangular net $3^{6}$ of anions (anions in position $\mathrm{A}$, cations in positions $\mathrm{B}$ or C). The distances Na1-As are equal $2.943 \AA$. Pairs of $\mathrm{Na} 2$ atoms perpendicular to the layer center the positions (B or C) left empty. Three distances Na2-As are equal $3.304 \AA$, one is equal $3.000 \AA$. The distances $\mathrm{Na} 2-\mathrm{Na} 2$ are also equal $3.000 \AA$. When $s$-s bonds form between $\mathrm{As}$ and $\mathrm{Na}$ atoms in a layer,

$$
\begin{aligned}
& r_{s}(\mathrm{Na} 1)=\sqrt{3} / 3 a-r_{s}(\mathrm{As})=1.226 \AA \text { and } \\
& r_{s}(\mathrm{Na} 2)=\sqrt{a^{2} / 3+c^{2} / 36}-r_{s}(\mathrm{As})=1.587 \AA .
\end{aligned}
$$

In such a manner

$$
r_{s}(\mathrm{As}): r_{s}(\mathrm{Na} 1): r_{s}(\mathrm{Na} 2)=1.000: 0.714: 0.924 \text {. }
$$

The structure of a $\mathrm{Na}_{3} \mathrm{As}$ cluster is shown in Fig. $11 \mathrm{~b}$.

\section{$\mathrm{Li}_{3} \mathrm{Bi}$ structure}

The $\mathrm{Li}_{3} \mathrm{Bi}$ structure $(a=6.722 \AA$ ) forms from the $\mathrm{CsCl}$ structure with double cell (Fig. 11c) by replacing half of the $\mathrm{Li}$ atoms in one of the simple cubic sublattices by $\mathrm{Bi}$ atoms. The $\mathrm{Bi}$ atoms form straight chains along the diagonals of the cube faces by $p-p$ bonds in the ground state. The radius of the $\mathrm{Bi}$ atoms is calculated as for the $\mathrm{NaCl}$ structure: 


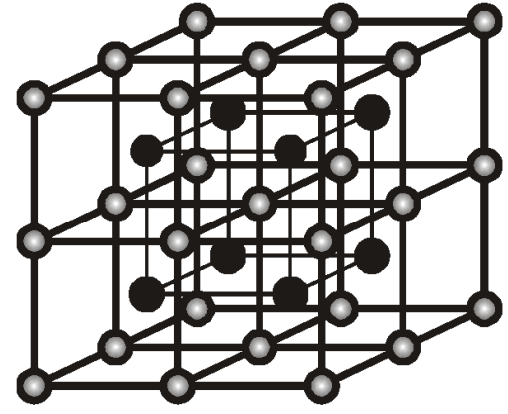

a)

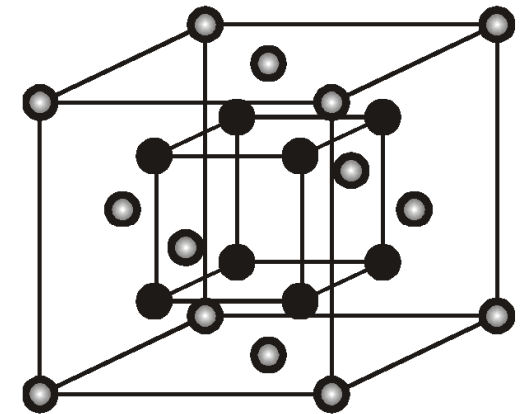

b)

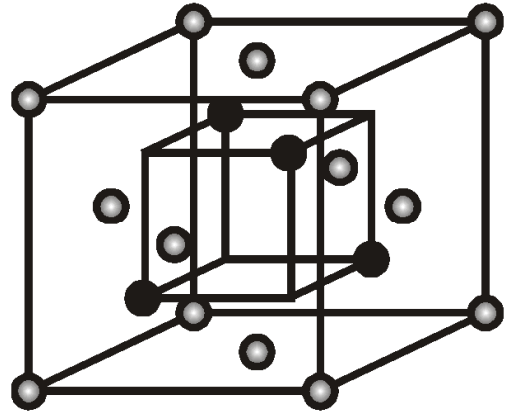

c)

Fig. 9 Formation of the $\mathrm{ZnS}$ structure (cubic): a) $\mathrm{CsCl}$ structure, b) $\mathrm{CaF}_{2}$ structure, c) $\mathrm{ZnS}$ structure.

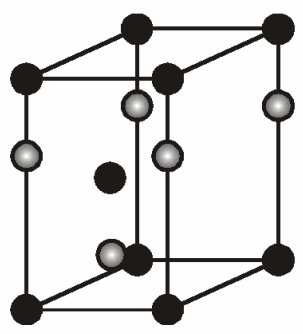

a)

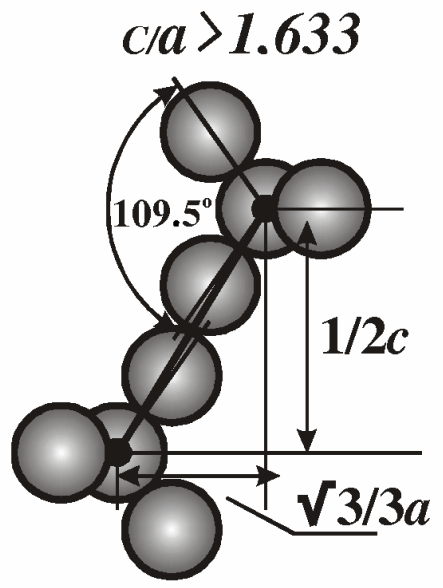

c)

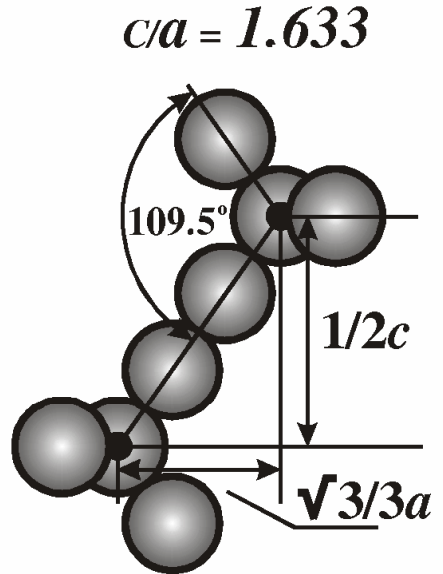

b)

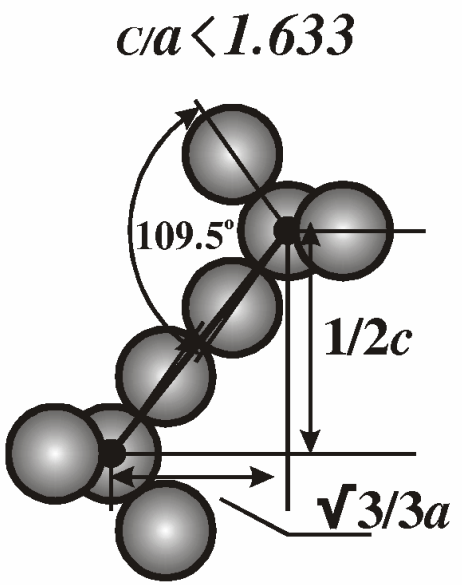

d)

Fig. 10 Calculation of the atomic radii in $\mathrm{ZnS}$ (hexagonal) structures: a) crystal structure, b) calculation of the atomic radii for $p-p$ bonds between anions for $c / a=1.633, \mathrm{c}$ ) for $c / a>1.633$, d) for $c / a<1.633$.

$r_{s}(\mathrm{Bi})=\frac{\sqrt{2}}{12 \times 0.5228} a=0.2254 a=1.515 \AA$.

When $s$-s bonds form between $\mathrm{Bi}$ and $\mathrm{Li} 1$ atoms the radius of the cation is calculated as for the $\mathrm{CaF}_{2}$ structure $\left.\left(r_{C} / r_{A}\right)=0.9207\right)$. It follows that $r_{s}(\mathrm{Li} 1)=r_{s}(\mathrm{Bi}) \times 0.9207=1.395 \AA$.
$\mathrm{Li}(2)$ and $\mathrm{Bi}$ atoms have equal dimensions.

\section{$\mathrm{TiO}_{2}$ structure}

In the structure of $\mathrm{TiO}_{2}$ rutile $(a=4.5937$, $c=2.9581 \AA, c / a=0.6439)$ the cations are surrounded by six anions disposed octahedrally (Fig. 12a). The octahedron is deformed. This structural type is of 


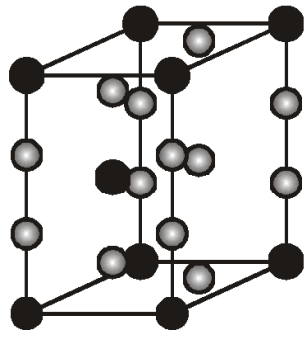

a)

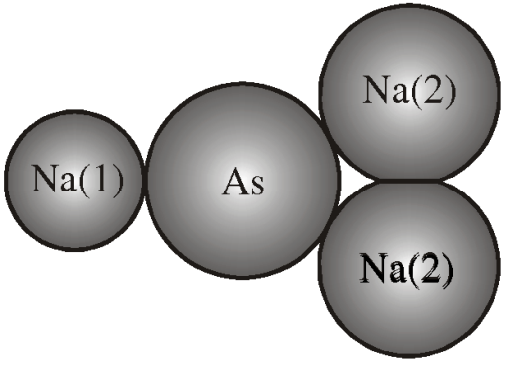

b)

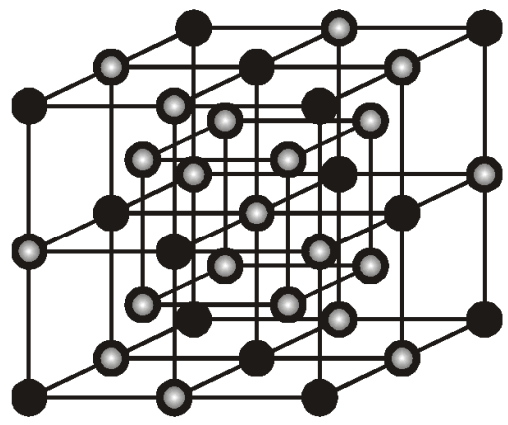

c)

Fig. 11 Structures of $M^{\mathrm{V}} N_{3}^{\mathrm{I}}$ phases: a) $\mathrm{Na}_{3} \mathrm{As}$ structure, b) a $\mathrm{Na}_{3} \mathrm{As}$ cluster, c) $\mathrm{Li}_{3} \mathrm{Bi}$ structure.

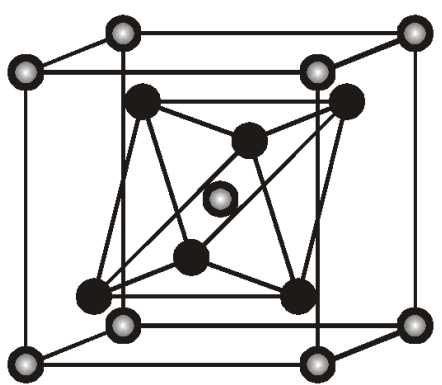

a)

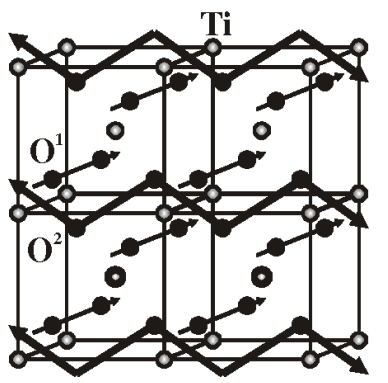

b)

Fig. 12 Crystal structure of $\mathrm{TiO}_{2}$ rutile: a) unit cell, b) system of chemical bonds.

Table 4 Atomic radii ( $\AA$ ) of elements of main groups III and V in ZnS structures.

\begin{tabular}{|c|c|c|c|c|c|}
\hline $\begin{array}{c}\text { Element } \\
\text { covalent } r \\
\text { ionic } r \text { [3] }\end{array}$ & $\begin{array}{c}N \\
r_{N}=0.73 \\
r_{A}=1.48\end{array}$ & $\begin{array}{c}P \\
r_{P}=1.11 \\
r_{A}=1.86\end{array}$ & $\begin{array}{c}A s \\
r_{A s}=1.23 \\
r_{A}=1.91\end{array}$ & $\begin{array}{c}S b \\
r_{S b}=1.43 \\
r_{A}=2.08\end{array}$ & $\begin{array}{c}B i \\
r_{B i}=1.50 \\
r_{A}=2.13\end{array}$ \\
\hline $\begin{array}{c}\mathbf{B} \\
\mathbf{r}_{\mathrm{B}}=\mathbf{0 . 8 9} \\
\mathbf{r}_{\mathrm{C}}=\mathbf{0 . 2 3}\end{array}$ & $\begin{array}{l}\text { (hex) } \\
0.818 \\
0.748\end{array}$ & $\begin{array}{l}\text { (cub) } \\
1.022 \\
0.941\end{array}$ & $\begin{array}{l}\text { (cub) } \\
1.077 \\
0.992\end{array}$ & & \\
\hline $\begin{array}{c}\mathrm{Al} \\
\mathrm{r}_{\mathrm{Al}}=\mathbf{1 . 4 3} \\
\mathrm{r}_{\mathrm{C}}=\mathbf{0 . 5 0}\end{array}$ & $\begin{array}{l}\text { (hex) } \\
0.977 \\
0.911\end{array}$ & $\begin{array}{l}\text { (cub) } \\
1.227 \\
1.131\end{array}$ & $\begin{array}{l}\text { (cub) } \\
1.268 \\
1.168\end{array}$ & $\begin{array}{l}\text { (cub) } \\
1.374 \\
1.266\end{array}$ & \\
\hline $\begin{array}{c}\mathbf{G a} \\
\mathrm{r}_{\mathrm{Ga}}=1.40 \\
\mathrm{r}_{\mathrm{C}}=\mathbf{0 . 6 2}\end{array}$ & $\begin{array}{l}\text { (hex) } \\
1.010 \\
0.934\end{array}$ & $\begin{array}{l}\text { (cub) } \\
1.228 \\
1.131\end{array}$ & $\begin{array}{l}\text { (cub) } \\
1.273 \\
1.172\end{array}$ & $\begin{array}{l}\text { (cub) } \\
1.376 \\
1.267\end{array}$ & \\
\hline $\begin{array}{c}\text { In } \\
r_{\text {In }}=1.66 \\
r_{C}=0.81\end{array}$ & $\begin{array}{l}\text { (hex) } \\
1.117 \\
1.037\end{array}$ & $\begin{array}{l}\text { (cub) } \\
1.324 \\
1.219\end{array}$ & $\begin{array}{l}\text { (cub) } \\
1.365 \\
1.258\end{array}$ & $\begin{array}{l}\text { (cub) } \\
1.460 \\
1.344\end{array}$ & \\
\hline $\begin{array}{c}\mathrm{Tl} \\
\mathbf{r}_{\mathrm{Tl}}=\mathbf{1 . 7 1} \\
\mathrm{r}_{\mathrm{C}}=\mathbf{0 . 9 5}\end{array}$ & & & & & \\
\hline
\end{tabular}

particular interest since the anions have two different valence states: one half of the anions (O1) form straight chains along the $c$-axis by $p$ - $p$ orbits in the ground state, whereas the second half of the anions (O2) form zigzag chains along the $a$-axis by $p$ - $p$ orbits in the state of orbital excitation, as shown in Fig. 12b. If the zigzag chains in neighboring layers are disposed orthogonally, the structure is tetragonal. If the zigzag chains are disposed equally in all layers, the structure is orthorhombic.
In the $\mathrm{TiO}_{2}$ structure $r_{s}(\mathrm{O} 1)=a / 6 \times 0.5228=0.943 \AA$.

The distance Ti-O1 is equal $1.949 \AA$ [3], from which $r_{s}(\mathrm{Ti})=1.006 \AA$.

The $\mathrm{O} 2$ anions in the $\mathrm{TiO}_{2}$ structure form three $s-s$ bonds with $\mathrm{Ti}$ atoms and their radii are easily calculated from the geometry:

$r_{s}(\mathrm{O} 2)=0.955 \AA$.

It results that

$r_{s}(\mathrm{Ti}): r_{s}(\mathrm{O} 1): r_{s}(\mathrm{O} 2)=1.000: 0.937: 0.949$. 
Table 5 Atomic radii ( $\AA$ ) of elements of main groups III and $\mathrm{V}$ in $\mathrm{Na}_{3} \mathrm{As}$ structures.

\begin{tabular}{|c|c|c|c|c|c|}
\hline $\begin{array}{l}\text { Element } \\
\text { covalent } r \\
\text { ionic } r \text { [3] }\end{array}$ & $\begin{array}{c}N \\
r_{N}=0.73 \\
r_{A}=1.48\end{array}$ & $\begin{array}{c}P \\
r_{P}=1.11 \\
r_{A}=1.86\end{array}$ & $\begin{array}{c}A s \\
r_{A s}=1.23 \\
r_{A}=1.91 \\
\end{array}$ & $\begin{array}{c}S b \\
r_{S b}=1.43 \\
r_{A}=2.08 \\
\end{array}$ & $\begin{array}{c}B i \\
r_{B i}=1.50 \\
r_{A}=2.13 \\
\end{array}$ \\
\hline $\begin{array}{c}\mathbf{L i} \\
\mathbf{r}_{\mathrm{Li}}=\mathbf{1 . 5 5} \\
\mathbf{r}_{\mathrm{C}}=\mathbf{0 . 6 8}\end{array}$ & & $\begin{array}{c}1.444 \\
1.017-1 \\
1.323-2\end{array}$ & $\begin{array}{c}1.489 \\
1.049-1 \\
1.364-2\end{array}$ & $\begin{array}{c}1.584 \\
1.130-1 \\
1.463-2\end{array}$ & $\begin{array}{c}\left.\mathbf{B i F}_{3}\right) \\
1.515 \\
1.395-1 \\
1.515-2\end{array}$ \\
\hline $\begin{array}{c}\mathrm{Na} \\
\mathrm{r}_{\mathrm{Na}}=1.89 \\
\mathbf{r}_{\mathrm{C}}=\mathbf{0 . 9 7}\end{array}$ & & $\begin{array}{c}1.678 \\
1.198-1 \\
1.550-2\end{array}$ & $\begin{array}{c}1.717 \\
1.226-1 \\
1.587-2\end{array}$ & $\begin{array}{c}1.809 \\
1.283-1 \\
1.664-2\end{array}$ & $\begin{array}{c}1.845 \\
1.307-1 \\
1.695-2\end{array}$ \\
\hline $\begin{array}{c}K \\
r_{K}=2.35 \\
r_{C}=1.33\end{array}$ & & $\begin{array}{c}1.918 \\
1.368-1 \\
1.770-2 \\
\end{array}$ & $\begin{array}{c}1.951 \\
1.391-1 \\
1.801-2\end{array}$ & $\begin{array}{c}2.039 \\
1.440-1 \\
1.870-2\end{array}$ & $\begin{array}{c}2.088 \\
1.486-1 \\
1.926-2 \\
\end{array}$ \\
\hline $\begin{array}{c}\mathbf{R b} \\
\mathbf{r}_{\mathrm{Rb}}=2.48 \\
\mathbf{r}_{\mathrm{C}}=1.47 \\
\end{array}$ & & & $\begin{array}{l}2.044 a \\
1.449-1 \\
1.880-2\end{array}$ & $\begin{array}{c}2.130 \\
1.496-1 \\
1.947-2\end{array}$ & $\begin{array}{c}2.179 \\
1.527-1 \\
1.990-2\end{array}$ \\
\hline $\begin{array}{c}C s \\
r_{\mathrm{Cs}}=2.68 \\
\mathbf{r}_{\mathrm{C}}=1.67\end{array}$ & & & & & \\
\hline
\end{tabular}

$c$-parameter obtained by interpolation

\section{Conclusions}

The results discussed above show that using a geometrical concept of the chemical bond allows not only to model a system of chemical bonds and to calculate real ionic radii in crystal structures, but leads to a series of important conclusions.

1) An ionic bond between atoms is formed only when an electron of one atom passes to a non-bonding orbit of another atom. The chemical bonds between anions and cations in ionic crystals are polar covalent.

2) The obtained models allow to calculate the real ionic radii of the atoms strictly from the parameters of the crystal structure. It is found that atoms of the same element that occupy different positions ( $\mathrm{Li}$ in $\mathrm{Li}_{3} \mathrm{Bi}$, $\mathrm{Na}$ in $\mathrm{Na}_{3} \mathrm{As}$, etc.) as a rule have different size. This is true also for atoms in different valence configurations. 3) Each crystal structure has its own ideal ratio of the sizes of cations and anions. The structure can be formed only by atoms capable of changing dimensions in accordance with the geometrical demands.

4) Phase transitions take place in cases where the capacity of the atom for polarization does obviously not correspond to strict structure ratios. It is found that the phase transitions $\mathrm{NaCl} \leftrightarrow \mathrm{CsCl}$ and $\mathrm{NaCl} \leftrightarrow \mathrm{ZnS}$ are controlled by the relation $r_{C} / r_{A}$, i.e. a size factor. The transition $\mathrm{ZnS}(\mathrm{cub}) \leftrightarrow \mathrm{ZnS}$ (hex) is connected with the change of valence state of the anions (ground state $\leftrightarrow$ orbital excitation). If this transition is not complete, polytypes form.

5) Analysis of experimental data shows that high pressure reduces the orbital excitation of atoms. This also leads to phase transitions (for example, $\mathrm{TiO}_{2} \leftrightarrow \mathrm{CaF}_{2}$ ).

\section{References}

[1] E.M. Slyusarenko, Prediction of chemical bonds in crystalline phases of inorganic materials, In: K.V. Frolov, I.F. Obraztsov, O.S. Sirotkin, V.S. Bogolyubov (Eds.), Theory and practice of technologies of manufacturing products of composite materials and new metal alloys - the $21^{\text {st }}$ century, Znanie, Moscow, 2003, pp. 179-186 (in Russian).

[2] E.M. Slyusarenko, V.T. Mosidze, Chemometrics and system analysis of modern problems in general chemistry, In: Progress in chemometrics research, Chapter 12, Nova Science Publishers, NY, 2005, pp. 151-189.

[3] S.S. Batsanov, Structural chemistry, facts and correlations, Dialog, Moscow, 2000 (in Russian).

[4] W.B. Pearson, The crystal chemistry and physics of metals and alloys. Vols. 1-2, Mir, Moscow, 1977 (in Russian).

[5] Reference book for chemists, Vol. 1, Goskhimizdat, Leningrad-Moscow, 1963 (in Russian).

[6] E. Parthé, Elements of inorganic structural chemistry, Mir, Moscow, 1993 (in Russian).

Proceeding of the X International Conference on Crystal Chemistry of Intermetallic Compounds, Lviv, September 17-20, 2007. 